\title{
IMPACT OF THE GRAND ETHIOPIAN RENAISSANCE DAM ON THE NILE LEVELS IN EGYPT
}

\author{
Amir M. Mobasher
}

Al-Azhar University, Faculty of Engineering, Civil Engineering Department, Cairo, Egypt

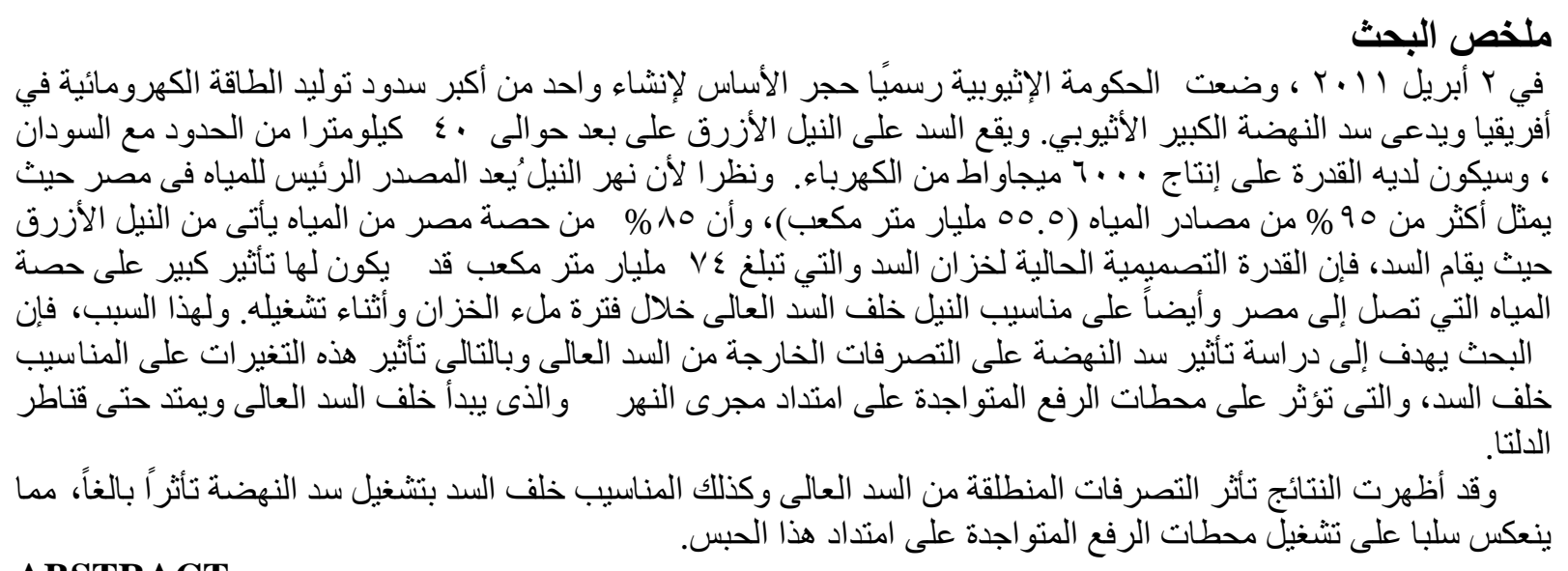
ABSTRACT

On April 2, 2011, Ethiopia Government formally launched what is expected to be the biggest hydroelectric power plant in Africa, called the Grand Ethiopian Renaissance Dam (GERD), it is located on the Blue Nile. Eighty-five per cent of Egypt's water share comes from the Blue Nile originating in Ethiopia. For this reason, this paper is proposed to study impacts of the GERD on the Nile flow to Egypt and the water levels and discharges downstream Aswan High Dam (AHD), and then estimate the effect of low water levels on irrigation pump stations. During this research, pump stations, for irrigation purposes, along the River Nile from Old Aswan Dam (OAD) to Delta barrage were reviewed according to their design and critical water level to determine the potential for expected problems due to passing low discharges due to GERD in the studied reaches. Finally specific conclusions were drawn.

Keywords: Grand Ethiopian Renaissance Dam, River Nile Discharges, Water Levels, Pump Stations.

\section{INTRODUCTION}

The River Nile is $6690 \mathrm{~km}$ long, extending through 35 degrees of latitude as it flows from south to north. Its basin covers approximately one-tenth of the African continent, with a catchment area of $3.3 \times 10^{6} \mathrm{~km}^{2}$ [2]. The River Nile flood has a very great variation due to the different characteristics of the Nile Basin. The Nile flood can be as high as $150 \times 10^{9} \mathrm{~m}^{3} / y e a r(1878 / 1879)$ and as low as $42 \times 10^{9} \mathrm{~m}^{3} /$ year (1913/1914). Both extreme cases, very low and very high, floods have their own side effects. While the very high floods have their side effects on river banks, hydraulic structures and riverbed, very low floods have their own side effects. Some examples of these side effects are the water supply un-sufficiency, navigation difficulties, and some local sedimentation problems [9]. 
Ethiopia intends to construct a huge Dam at its border with Sudan country which called GERD. It is known that $85 \%$ of Egypt historical water share comes from the Abbay / Blue and the Tekezi /Atbara Rivers [5]. Fears started to grow due to the fact that the impacts of such dam might affect Egypt's share. For this reason, this research was initiated with the objective of studying the impact of the Ethiopian Dam on the water levels and discharges downstream AHD and the effect of low water levels on irrigation pump stations.

At the beginning Aswan High Dam Reservoir (AHDR) operations rules were modelled using a new approach to illustrate and evaluate this impact by developing a special mathematical model. This model is based on mass balance hydrologic routing equation. This regression equation based on actual data of water discharges and head relationships. The calculation considered the behaviour of AHDR, water inflows, out flows, all losses and quota of Sudan from The River Nile.

This step was followed by using a one-dimensional computer program based on solving the flow equations to compute water levels related to the analyzed discharged. The used mathematical model for this analysis is GSTARS 2.0 Model which was developed by the U.S. Bureau of Reclamation in 1998 and then calibrated using the actual water level readings from gauging stations after developing the corresponding rating curve for each station. The computed water levels were compared to the design and critical pump stations water levels to determine the adequacy of the water level for pump station supply. Many different scenarios were considered during this analysis and the resulted water level and discharge changes were highlighted.

\section{STUDY REACHES CHARACTERISTICS}

The River Nile from Aswan to Delta Barrages is divided into four major reaches between each two hydraulic structures. These four reaches are; First Reach is located between OAD and Esna Barrage with a total length of 167 kilometer. Second Reach is located between Esna Barrage and Naga Hammadi Barrage with a total length of 192 kilometer. Third Reach is located between Naga Hammadi Barrage and Assiut Barrage with a total length of 186 kilometer. Fourth Reach is located between Assiut Barrage and Delta Barrages with a total length of 409 kilometer [12].

Besides the gravity diversion of Nile water upstream of each above -mentioned barrages, water is also diverted by more than 100 major pumping stations along the Nile from OAD to Delta Barrages and its branches (Table 1) [11]. Some of the irrigation pump stations along the four reaches are floating stations, therefore; they were not affected by the change of water level. Some other stations are constructed for high flow; therefore, they are not operated during normal and low flows [12].

Table 1: Major pumping stations [11].

\begin{tabular}{|l|c|c|}
\hline \multicolumn{1}{|c|}{ Nile reach } & Number of pumping stations & Total Discharge $\left(\mathbf{m}^{\mathbf{3}} / \mathbf{s}\right)$ \\
\hline Aswan - Esna & 60 & 95.13 \\
\hline Esna - Naga Hamadi & 8 & 41.22 \\
\hline Naga Hamadi - Assiut & 4 & 15.86 \\
\hline Assiut - Delta Barrage & 33 & 12.68 \\
\hline
\end{tabular}

3. GRAND ETHIOPIAN RENAISSANCE DAM (GERD)

GERD is located on the Blue Nile (known locally as the River Abbay); about $40 \mathrm{~km}$ east of Sudan. GERD will generate an artificial lake with a holding capacity of $74 \times 10^{9} \mathrm{~m}^{3}$ of water at the full supply level, almost 1.5 times the annual flow of the Blue Nile $\left(49 \times 10^{9} \mathrm{~m}^{3} /\right.$ year $)$, and covers an area of $1,680 \mathrm{~km}^{2}$, which ultimately will be used for electric power generation. The power plant, expected to generate around 6,000 megawatt (MW). The dam is designed with dimensions of $145 \mathrm{~m}$ high and $1,800 \mathrm{~m}$ long $[5,10]$. 


\section{IMPACT OF GERD ON THE DISCHARGES DOWNSTREAM AHD}

\subsection{Simulation Model}

To identify the effects of GERD on the discharges downstream AHD, AHDR is modeled and its operation is simulated and coded in FORTRAN language to predict the relation between the inflow to the reservoir and the discharges downstream AHD. The developed approach was used in this study to analyze the actual occurring conditions for different scenarios. This model is based on mass balance of hydrologic routing equations as follows [3]:

$$
\begin{gathered}
\frac{d S}{d t}=I-O \\
\frac{d H}{d t}=\frac{I-O}{S_{a}(H)}
\end{gathered}
$$

Where:

$$
\begin{aligned}
& S=\int_{0}^{H} S_{a}(H) d H \\
& \frac{d S}{d t}=\frac{d S}{d H} \frac{d H}{d t}
\end{aligned}
$$

$$
\frac{d H}{d t}=\frac{\sum Q_{\text {in }}-\sum Q_{\text {out }}}{S_{a}(H)}
$$

Where:

$\boldsymbol{d H} / \boldsymbol{d t} \quad$ : The change of the reservoir water level with respect to time.

$\sum \boldsymbol{Q}_{\text {in }} \quad:$ The summation of the inflow to the reservoir.

$\sum \boldsymbol{Q}_{\text {out }} \quad$ : The summation of the outflow from the reservoir.

$\boldsymbol{S a}(\boldsymbol{H})$ : Reservoir water surface as a function of $\mathrm{H}\left(\mathrm{m}^{2}\right)$.

$\boldsymbol{S} \quad:$ The volume of the reservoir storage water $\left(\mathrm{m}^{3}\right)$.

I $\quad$ : Inflow in the reservoir ( $\mathrm{m}^{3} /$ day).

$\boldsymbol{O} \quad$ : Outflow from the reservoir $\left(\mathrm{m}^{3} /\right.$ day).

\subsubsection{Simulation procedures}

The general procedure for simulation of AHDR involves:

- The computations of inflow hydrograph are performed. These computations are based on the historical monthly distribution of similar inflow floods to form an inflow hydrograph of the required amount and more realistic distribution.

- The computations of the proposed outflow hydrograph downstream AHD are based on the water requirements for different months, the restrictions of the allowable maximum outflow downstream the dam, and the maximum allowed water levels upstream the dam. So the basic outflow hydrograph is composed from the historical data and water demand and water discharges and levels restrictions.

- The model monitors both; the upstream water level and the outflow downstream the dam. The task is to ensure that the maximum water level upstream the dam is not exceeding the maximum limit during any time step and, also, to avoid increasing of the outflow discharge downstream the dam higher than the safe limits if possible. 
- For Toshka spillway, the empirical regression functions for Toshka spillway and water levels are used for this simulation.

- The major AHDR losses are the evaporation losses. The evaporation losses are computed according to reservoir water levels, surface area, climatic conditions and time of the year. Because the seepage to the groundwater system is relatively small compared to other terms, it is not consider in the simulation process.

- The proposed hydrograph computations for South Valley Project (Toshka Project) are introduced. According to the water requirements of the cultivated area based on the requirements of similar crops cultivated on similar environment.

- The simulation time step for all variables is one month.

\subsubsection{Simulation constraints}

The model constraints include:

- The water levels upstream AHD should be kept at $175.00 \mathrm{~m}$ at the beginning of water year (August $1^{\text {st }}$ ) to fulfill high and low flood requirements.

- The minimum allowed water discharges should be released to fulfill irrigation, navigation, drinking and other requirements and Sudan abstractions.

- The maximum capacity of AHDR, which amounts to $162 \times 10^{9} \mathrm{~m}^{3}$ is divided into three parts as follows: dead storage capacity of $31.6 \times 10^{9} \mathrm{~m}^{3}$ up to 147 meter above Mean Sea Level and designed for the silt deposition over 500 years, live or working storage capacity between the levels 147 and $175 \mathrm{~m}$ above MSL, mounting to $90.4 \times 10^{9} \mathrm{~m}^{3}$, which guarantees the annual requirements of water, and flood control capacity of $40 \times 10^{9} \mathrm{~m}^{3}$ between levels 175 and $182 \mathrm{~m}$ above MSL [6]. Figure 1 shows the management and operation zones of AHDR.



Fig. 1: Management and operation zones of AHDR.

- maximum allowed water outflow should not exceed 250-300 x $10^{6} \mathrm{~m}^{3} /$ day to avoid excessive erosion and banks overtopping.

- The present water demand for Toshka Project (South Valley Project) is $5.1 \times 10^{9} \mathrm{~m}^{3}(14 \mathrm{x}$ $10^{6} \mathrm{~m}^{3} /$ day), this amount is taken directly from AHDR through pumping [11]. 


\subsubsection{Data used for simulation}

\subsubsection{Stream flow data}

Annual inflow records at Dongola in Sudan (representing the inflow to AHDR [14]) have been published by Ghaas, 1998 and Sutcliffe \& Parks, 1999, in order to get an idea about the high and low flows for 83 years during the period from 1912 to 1994 (Figure 2). The mean flow varied significantly depending upon the period considered, the mean annual flow from 1912-1964 (before operation of AHD) was $2754 \mathrm{~m}^{3} / \mathrm{s}\left(86.86 \times 10^{9} \mathrm{~m}^{3}\right)$ with a standard deviation of $398 \mathrm{~m}^{3} / \mathrm{s}$ $\left(12.56 \times 10^{9} \mathrm{~m}^{3}\right)$. The mean annual flow from 1965-1994 (after operation of AHD), on the other hand, was $2214 \mathrm{~m}^{3} / \mathrm{s}\left(69.81 \times 10^{9} \mathrm{~m}^{3}\right)$ with a standard deviation of $443 \mathrm{~m}^{3} / \mathrm{s}\left(13.98 \times 10^{9} \mathrm{~m}^{3}\right)$.

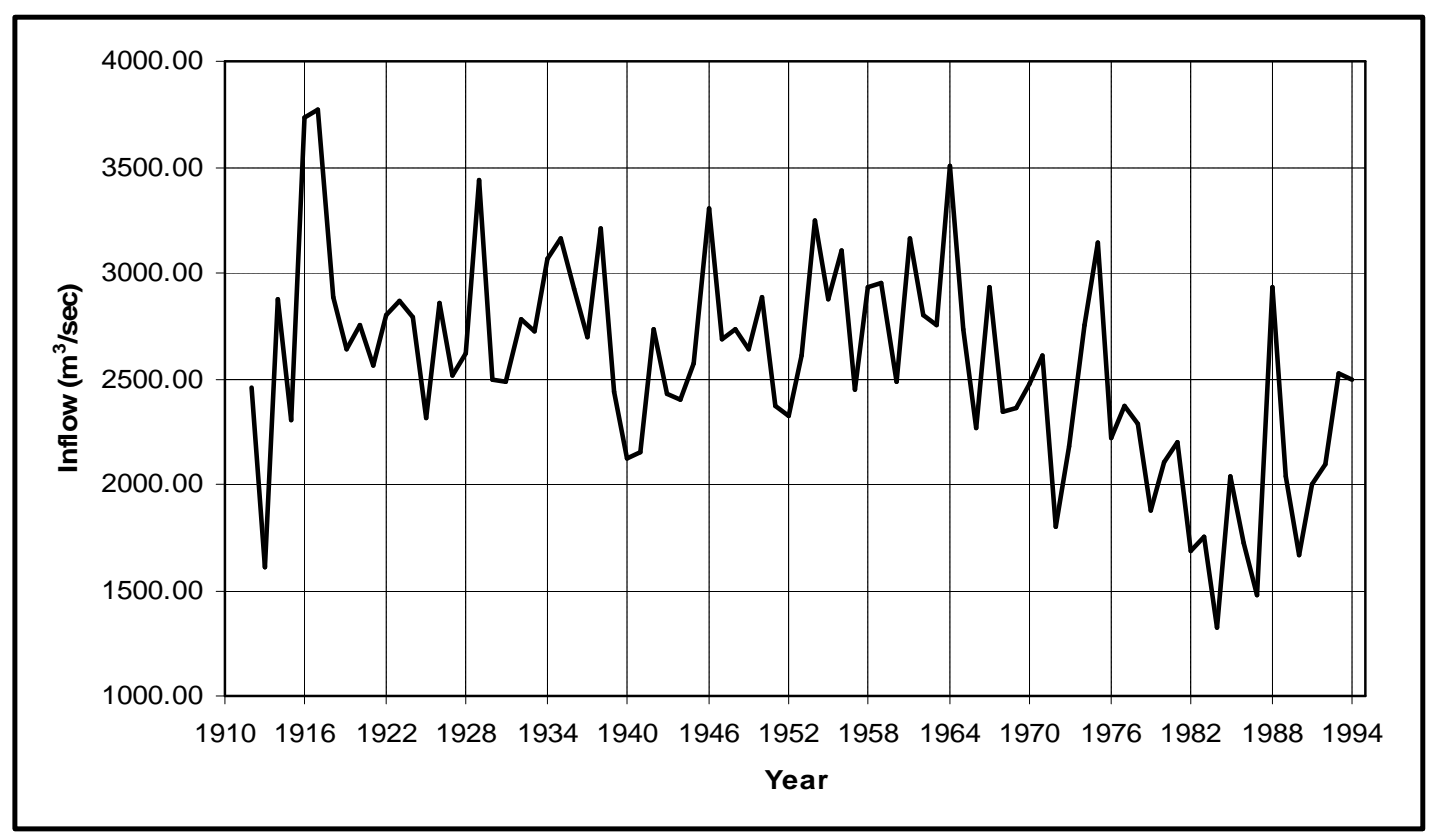

Fig. 2: The Average Annual Inflow of the Historical Data at Dongola from (1912-1994) [8, 13$]$.

\subsubsection{Water users data and Evaporation losses}

The release from the AHDR is the annual share of Egypt according to the treaty with Sudan (55.5 $\mathrm{x} 109 \mathrm{~m} 3$ ) plus possibly the volume released for safety reasons if the water level in the reservoir becomes very high. The annual evaporation losses from the reservoir are divided between the months, the highest evaporation rates from the reservoir occur in May-October, while the lowest values occur in the period December-February. The monthly releases from AHDR and reservoir evaporation which used in this simulation is shown in Table 2.

Table 2: Monthly Releases from AHD and Reservoir evaporation $[8,13]$.

\begin{tabular}{|l|l|l|l|l|l|l|l|l|l|l|l|l|}
\hline & Jan & Feb & Mar & Apr & May & Jun & Jul & Aug & Sep & Oct & Nov & Dec \\
\hline $\begin{array}{l}\text { Monthly Releases } \\
\text { from AHD }\left(\mathbf{m}^{3} / \mathbf{s}\right)\end{array}$ & 1347 & 1587 & 1720 & 1701 & 1908 & 2513 & 2581 & 2095 & 1469 & 1422 & 1430 & 1347 \\
\hline $\begin{array}{l}\text { AHDR evapora- } \\
\text { tion (mm/day) }\end{array}$ & 4.10 & 4.27 & 5.60 & 6.53 & 8.10 & 8.73 & 8.67 & 8.47 & 7.90 & 7.13 & 5.53 & 4.43 \\
\hline
\end{tabular}




\subsubsection{3. (Area - Elevation - Storage) equations}

The water level upstream AHD defines the surface area and the volume of water in the reservoir. The base equations of the model is [6]:

$$
E l=79.9734+0.0369801 \mathrm{~V}+18.8705 \ln V
$$

Where:

$$
S a=-3164.28+25.4914 V+1092.92 \ln V
$$

$\boldsymbol{V}:$ The reservoir storage in $10^{9} \mathrm{~m}^{3}$.

$\boldsymbol{E l}$ : The reservoir elevations in meters.

$\mathrm{Sa}$ : The reservoir surface area $\mathrm{Km}^{2}$.

4.1.3.4. Toshka spillway outflow

Using the measured data of the water level upstream the AHD and the discharge of the Ogee weir for Toshka spillway for flood of year (1998/1999), a linear regression analysis equation is obtained by Abdel-Moteleb and Saad (2001). The equation is as follows [1]:

$$
Q=519.84 H-93028
$$

Where:

$$
\begin{aligned}
\boldsymbol{Q} & : \text { The discharge in } \mathrm{m}^{3} / \mathrm{s} \text {. } \\
\boldsymbol{H} & : \text { The water levels upstream the AHD in meters. }
\end{aligned}
$$

\subsection{GERD Dam Filling Scenarios}

In the present study, the simulation model was tested for six scenarios of filling of GERD reservoir, in order to assess the sensitivity of the discharges downstream AHD in terms of filling period length. Three, four, five, six, seven and eight years filling period was simulated by considering current operation rules for AHD reservoir (Table 3).

Table 3: Scenarios for filling period of GERD and change in stream flow at Dongola (the entrance of AHDR) used in the simulation.

\begin{tabular}{|c|c|c|c|c|c|c|}
\hline Scenarios & $\mathbf{1}$ & $\mathbf{2}$ & $\mathbf{3}$ & $\mathbf{4}$ & $\mathbf{5}$ & $\mathbf{6}$ \\
\hline Filling Period & 3 years & 4 years & 5 years & 6 years & 7 years & 8 years \\
\hline $\begin{array}{c}\text { Flow at Dongola } \\
\left(\mathbf{1 0} \mathbf{~ m}^{\mathbf{3}} / \text { year }\right)\end{array}$ & 45.14 & 51.31 & 55.01 & 57.48 & 59.24 & 60.56 \\
\hline
\end{tabular}

\subsection{An Assessment of The impact of The filling Period of GERD on The discharges downstream AHD}

Simulations were undertaken to assess the impacts of GERD on the discharges downstream AHD during filling periods. Impacts are assessed based on the local situations and the consideration of the basin as a system for selected mean flow. Comparative analysis of AHD operation results for the current situation and AHD with GERD has been conducted. The mean annual withdrawal from AHDR for the six filling period scenarios are 45.02, 47.70, 49.32, 50.39, 51.16 and $51.74 \mathrm{x}$ $10^{9} \mathrm{~m}^{3}$, respectively for three, four, five, six , seven and eight years filling period of GERD respectively, compared to the baseline release of $55.50 \times 10^{9} \mathrm{~m}^{3}$ (Figures 3,4 ). The results show significant potential deficits for scenario 6 (filling period 8 years), the annual deficits would be $3.76 \times 10^{9} \mathrm{~m}^{3}$. The annual deficit might grow and reaches to $10.48 \times 10^{9} \mathrm{~m}^{3}$ for scenario 1 (filling period 3 years). 


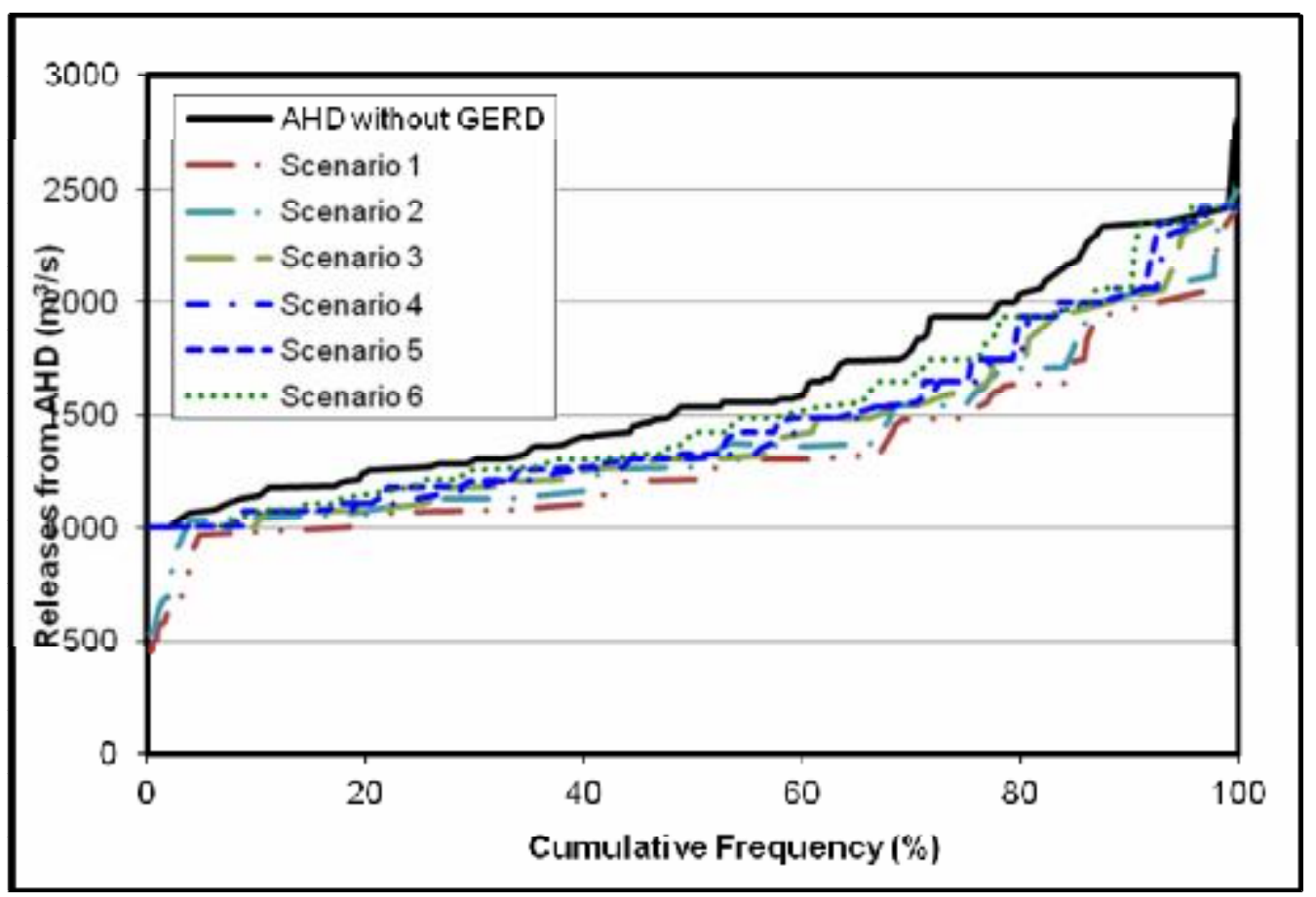

Fig. 3: Frequency curve of releases downstream AHD.

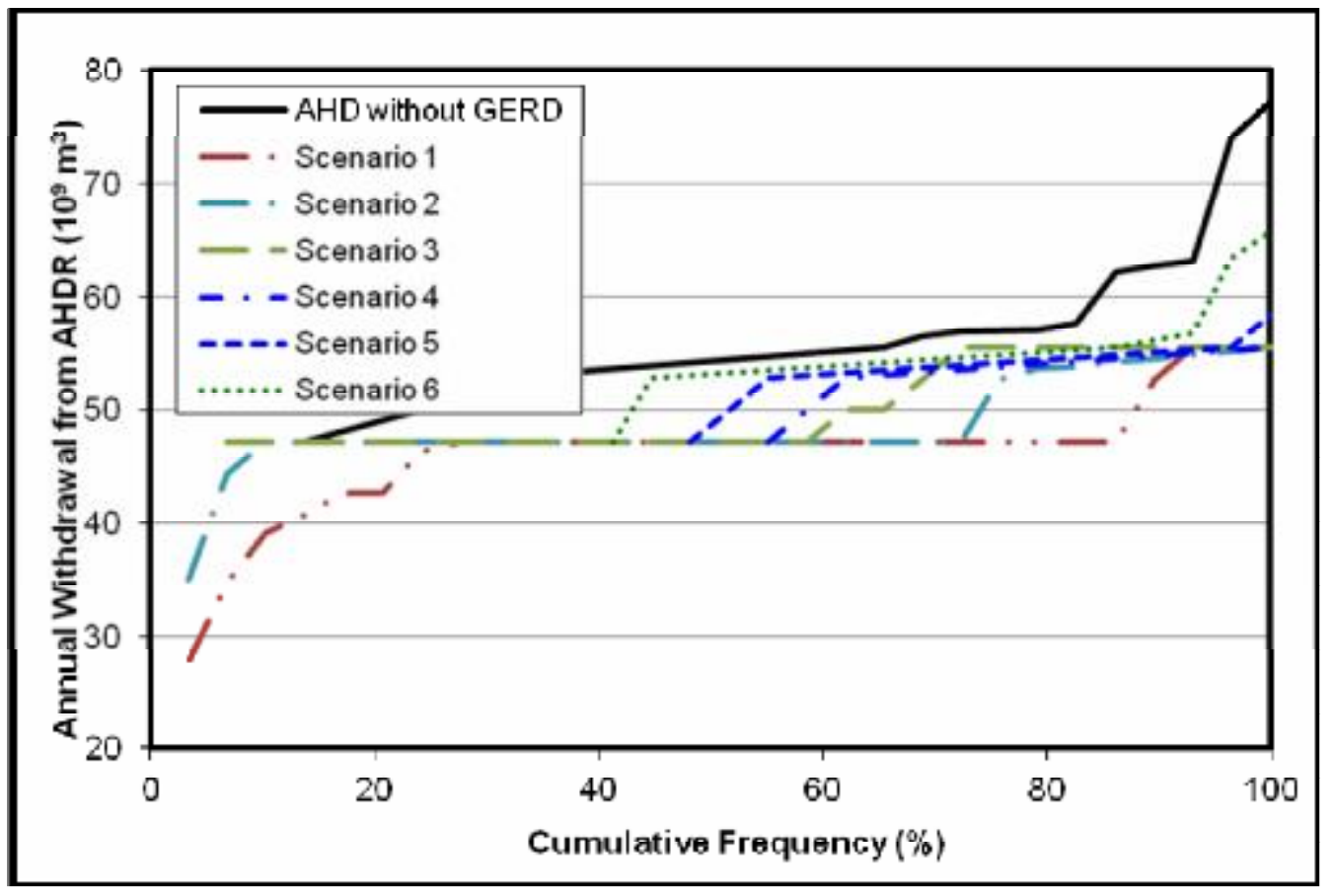

Fig. 4: Frequency curve of annual withdrawal from AHDR.

Excluding withdrawals for the Toshka project, taken directly from AHDR, the water discharges downstream AHD would amount to 39.92, 42.61, 44.22, 45.29, 46.06, and $46.63 \times 10^{9} \mathrm{~m}^{3}$, respectively. Table 4 presents the average monthly releases downstream AHD for the six scenarios 
$(1,2,3,4,5$ and 6$)$. The maximum discharges (occurring in July) for the six scenarios $(1,2,3,4$, 5 and 6) are 173, 186,195, 198, 198 and $200 \times 10^{6} \mathrm{~m}^{3} /$ day, respectively. The minimum discharges (occurring in December) for the six scenarios (1, 2, 3, 4, 5 and 6) are 67, 70, 71, 75, 77 and $79 x$ $10^{6} \mathrm{~m}^{3} /$ day, respectively (Table 4).

This study focused on the effect of passing the lowest releases from AHDR (i.e. during December) on the pump stations along the four reaches. The proposed discharges for the four reaches are presented in Table 5.

Table 4: Average monthly releases from AHDR $\left(10^{6} \mathrm{~m}^{3} / \mathrm{day}\right)$ (for the first reach) for the modelled scenarios.

\begin{tabular}{|c|c|c|c|c|c|c|c|c|c|c|c|c|}
\hline $\begin{array}{c}\text { Scenar- } \\
\text { ios }\end{array}$ & Jan & Feb & Mar & Apr & May & Jun & Jul & Aug & Sep & Oct & Nov & Dec \\
\hline 1 & 80 & 90 & 98 & 93 & 127 & 160 & 173 & 154 & 101 & 85 & 83 & 67 \\
\hline 2 & 85 & 94 & 106 & 99 & 136 & 172 & 186 & 166 & 108 & 91 & 87 & 70 \\
\hline 3 & 87 & 97 & 108 & 102 & 142 & 179 & 195 & 173 & 111 & 93 & 90 & 71 \\
\hline 4 & 91 & 100 & 112 & 105 & 145 & 182 & 198 & 176 & 115 & 97 & 93 & 75 \\
\hline 5 & 93 & 105 & 113 & 107 & 147 & 183 & 198 & 177 & 116 & 98 & 96 & 77 \\
\hline 6 & 93 & 107 & 115 & 109 & 148 & 185 & 200 & 178 & 118 & 100 & 97 & 79 \\
\hline
\end{tabular}

Table 5: The proposed discharges for this analysis $\left(10^{6} \mathrm{~m}^{3} / \mathrm{day}\right)$.

\begin{tabular}{|l|c|c|c|c|c|c|}
\hline $\begin{array}{c}\text { Scenarios } \\
\text { Reaches }\end{array}$ & 1 & 2 & 3 & 4 & 5 & 6 \\
\hline Reach 1 & 67 & 70 & 71 & 75 & 77 & 79 \\
\hline Reach 2 & 57 & 60 & 61 & 65 & 67 & 69 \\
\hline Reach 3 & 47 & 50 & 51 & 55 & 57 & 59 \\
\hline Reach 4 & 44.7 & 47.7 & 48.7 & 52.7 & 54.7 & 56.7 \\
\hline
\end{tabular}

\section{Water Level Computations Using Gstars 2.0 Model}

The used mathematical model for this analysis is GSTARS 2.0 Model which was developed by the U.S. Bureau of Reclamation in 1998. This model has a number of capabilities such as:

- It has the capability of computing hydraulic parameters for open channels for fixed and movable bed boundaries.

- It has the capability of computing water surface profile for subcritical, super critical and mixed type flow.

- It has the capability of predicting and simulating the change of alluvial channel profile and cross sectional geometry.

\subsection{Backwater Computions}

GSTARS 2.0 solves the energy equation based on the standard step method for backwater computations. For cases of change between subcritical and supercritical flow conditions, the momentum equation is used instead.

\subsection{Energy Equation}

For water profile computations, the energy equation used is [4]:

Where:

$$
Z_{1}+Y_{1}+\alpha_{1} \frac{V_{1}^{2}}{2 g}=Z_{2}+Y_{2}+\alpha_{2} \frac{V_{2}^{2}}{2 g}+H_{t}
$$




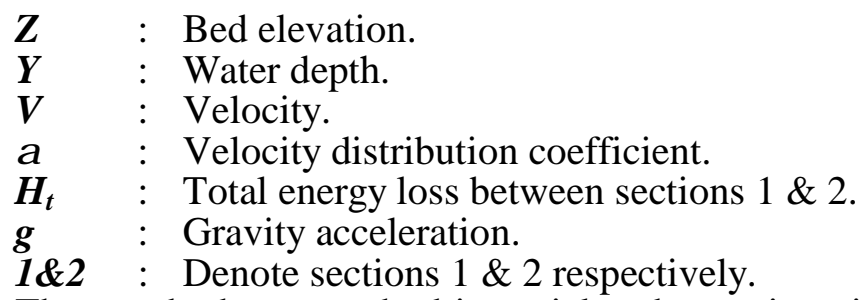

The standard step method is a trial and error iterative procedure for solving energy equation for water surface profile.

\subsection{Momentum Equation}

The momentum equation is used for flow regime change, which means that the flow will change from subcritical to supercritical or vise versa. The momentum equation is:

Where:

: Unit weight of water.

$$
\frac{Q \gamma}{g}=\left(\beta_{2} V_{2}-\beta_{1} V_{1}\right)=p_{1}-p_{2}+W \sin \theta-F_{f}
$$

$\beta \quad:$ Momentum coefficient.

$\theta \quad$ : Angle of inclination of channel.

$\boldsymbol{W} \quad$ : Weight of water enclosed between sections $1 \& 2$.

$\boldsymbol{F}_{f} \quad$ : Total external friction force acting along the channel boundaries.

\subsection{Model Calibration}

The first step of model application is to calibrate the model for water levels and this step is important step to get roughness coefficient " $n$ ". The following data are entered to the model as input files:

(A) Cross sections geometry and locations.

The cross sections were extracted from the hydrographic and topographic maps produced by the Nile Research Institute during the period from 2003 to 2009.

(B) Discharge time relationship.

The daily discharge and the daily water level according these discharges for all the gauging stations are used to develop the rating curves.

(C) Cross section bed grain size distribution.

(D) Boundary condition for each flow.

The discharge downstream the barrages (upstream boundary condition) and the upstream water level of the barrages according to these discharges (downstream boundary condition).

The value of Manning coefficient " $n$ " is basically depends on many factors:

1 - The geometric properties of the cross sections.

2- The discharges through the study reach and the water levels corresponding it.

3- The available data of sediment transport.

Calibration is an important process to tune the model parameter in order to force the model to produce results nearly similar to the measured ones. Calibration is an effort to better parameterize a model to a given set of local conditions, thereby reducing the prediction uncertainty. Model calibration is performed by carefully selecting values for model input parameters (n Manning coefficient) by comparing model predictions (output) for a given set of assumed conditions with observed data for the same conditions. Different gauging stations along each reach were used for this calibration. These gauging stations are presented in Table 6. 
Table 6: Selected water level gauging stations [12].

\begin{tabular}{|c|c|c|c|c|c|}
\hline No. & Site Name & Km & No. & Site Name & Km \\
\hline R 1-1 & Gaafra & $\mathbf{3 3 . 7 5}$ & R 3-5 & Sohag & $\mathbf{4 4 5 . 9 5}$ \\
\hline R 1-2 & Kom Ombo & 49.65 & R 3-6 & Koramat & $\mathbf{4 5 7 . 6 0}$ \\
\hline R 1-3 & Ekleet & $\mathbf{6 2 . 4 5}$ & R 3-7 & Maragha & $\mathbf{4 7 0 . 0 0}$ \\
\hline R 1-4 & Salwa Bahry & $\mathbf{8 5 . 4 5}$ & R 3-8 & Khazend & $\mathbf{4 7 9 . 1 0}$ \\
\hline R 1-5 & Ramady & $\mathbf{1 0 2 . 5 0}$ & R 3-9 & Magris & $\mathbf{5 0 9 . 5 0}$ \\
\hline R 1-6 & Baseles & $\mathbf{1 3 1 . 0 0}$ & R 3-10 & Aboteeg & $\mathbf{5 2 0 . 5 0}$ \\
\hline R 1-7 & U.S. Esna & $\mathbf{1 6 6 . 6 5}$ & R 3-11 & U.S. Assiut & $\mathbf{5 4 4 . 7 8}$ \\
\hline R 2-1 & D.S. Esna & $\mathbf{1 6 6 . 6 5}$ & R 4-1 & D.S. Assiut & $\mathbf{5 4 4 . 7 8}$ \\
\hline R 2-2 & Mateena & $\mathbf{1 7 4 . 7 0}$ & R 4-2 & Maaabda & $\mathbf{5 7 6 . 2 0}$ \\
\hline R 2-3 & Armant & $\mathbf{2 0 3 . 8 0}$ & R 4-3 & Mandra & $\mathbf{6 1 2 . 1 0}$ \\
\hline R 2-4 & Luxor & $\mathbf{2 2 4 . 1 0}$ & R 4-4 & Menia & $\mathbf{6 8 7 . 5 5}$ \\
\hline R 2-5 & Hela & $\mathbf{2 5 5 . 6 0}$ & R 4-5 & Fadl & $\mathbf{7 3 5 . 2 5}$ \\
\hline R 2-6 & Sharikia & $\mathbf{2 6 4 . 9 0}$ & R 4-6 & Beba & $\mathbf{7 8 9 . 0 0}$ \\
\hline R 2-7 & Qena & $\mathbf{2 8 6 . 7 0}$ & R 4-7 & Baniswafe & $\mathbf{8 0 8 . 6 0}$ \\
\hline R 2-8 & Naga Hamadi & $\mathbf{3 4 6 . 4 5}$ & R 4-8 & Korimate & $\mathbf{8 3 9 . 1 0}$ \\
\hline R 2-9 & U.S. Naga & $\mathbf{3 5 9 . 4 8}$ & R 4-9 & Lethy & $\mathbf{8 7 3 . 7 0}$ \\
\hline R 3-1 & D.S. Naga & $\mathbf{3 5 9 . 4 8}$ & R 4-10 & Eksas & $\mathbf{8 8 7 . 0 0}$ \\
\hline R 3-2 & Dom & $\mathbf{3 6 3 . 2 0}$ & R 4-11 & Roda & $\mathbf{9 2 7 . 0 0}$ \\
\hline R 3-3 & Baliana & $\mathbf{3 8 6 . 6 0}$ & R 4-12 & D.S. Delta & $\mathbf{9 5 3 . 0 0}$ \\
\hline R 3-4 & Gerga & 405.10 & & & \\
\hline
\end{tabular}

The model runs for 10 days for each scenario to be sure that the model will reach to the steady state condition (the proposed discharge passing through the whole of the study reach from upstream to downstream). The calibration is followed by a verification process. The field data was split into 2 groups (one group for the calibration and the other for verification). To verify the model after completing its calibration, the model was re-run under another flow condition and using the same calibration parameters (Manning coefficient) and comparing the results with "observed" data for the new flow condition.

Figure 5 provides the calibration results for the first scenario for the four reaches. From this figure it can be concluded that there is a close agreement between the measured and the predicted water levels. Confident with the calibration process, simulation process was initiated from which results were obtained.

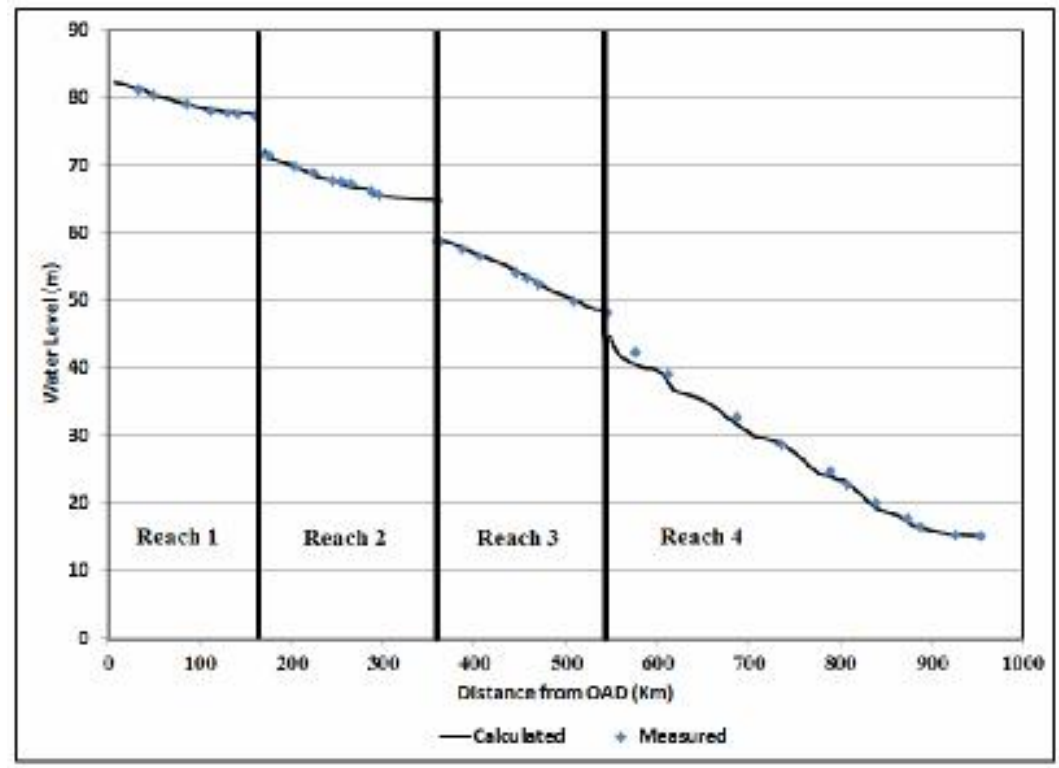

Fig. 5: Model Calibration Results for first scenario. 


\subsection{Results and Analysis for the different scenarios}

Figure 6 shows the results for different scenarios for the first reach. It indicates the critical operation level for the fixed pump stations. If the station is subjected to any of the studied scenarios, it could be operated under this scenario. If the critical operation level for the station is located above any scenario, it means that the station will not be operated under this scenario during the time with the discharge used in the computation. The results identified the percentage of pumps on the first reach that will not operate under the effect of the six scenarios $(1,2,3,4,5$ and 6$)$ would be $47 \%, 45 \%, 43 \%, 36 \%, 33 \%$ and $23 \%$, respectively. Figure 7 shows the results for the different scenarios for the second reach, this figure shows the critical operation level for the fixed stations. The results indicated the percentage of pumps on the second reach that will not operate for the five scenarios $(1,2,3,4$, and 5) would be $41 \%, 35 \%, 35 \%, 29 \%, 28 \%$ and 28 $\%$, respectively. Figure 8 shows the results for the different scenarios for the third reach, this figure indicated the critical operation level for the fixed stations. The results indicated the percentage of pumps on the third reach that will not operate for the five scenarios $(1,2,3,4,5$ and 6$)$ would be $50 \%$ for all scenarios. Figure 9 shows the results for the different scenarios for the fourth reach. It shows the critical operation level for the fixed stations. The results indicated the percentage of pumps on the fourth reach that will not operate for the five scenarios $(1,2,3,4,5$ and 6) would be $54 \%$ for all scenarios.

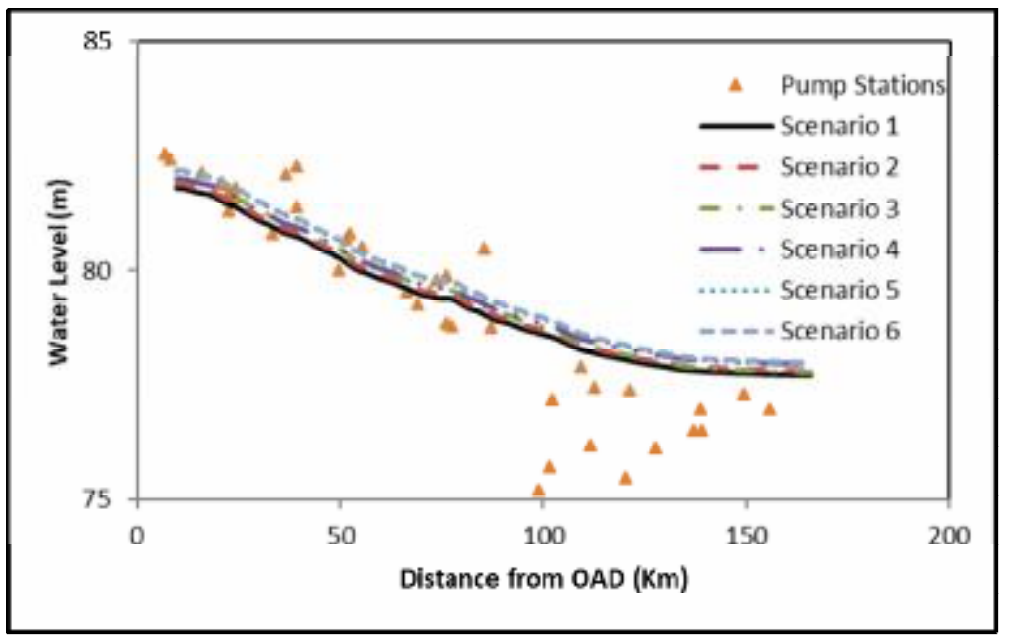

Fig. 6: Analysis results for the first reach.

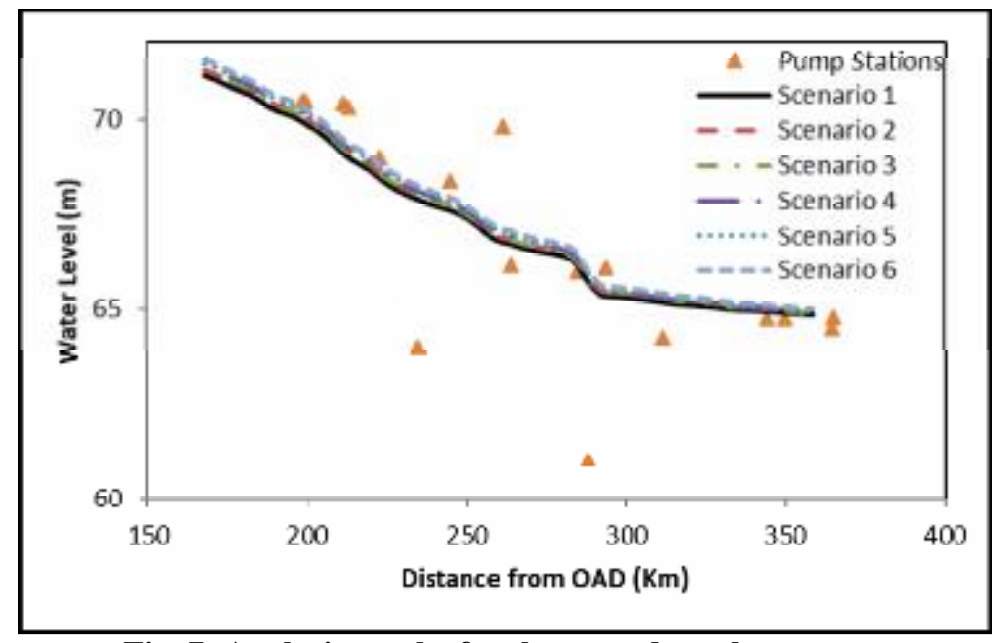

Fig. 7: Analysis results for the second reach. 


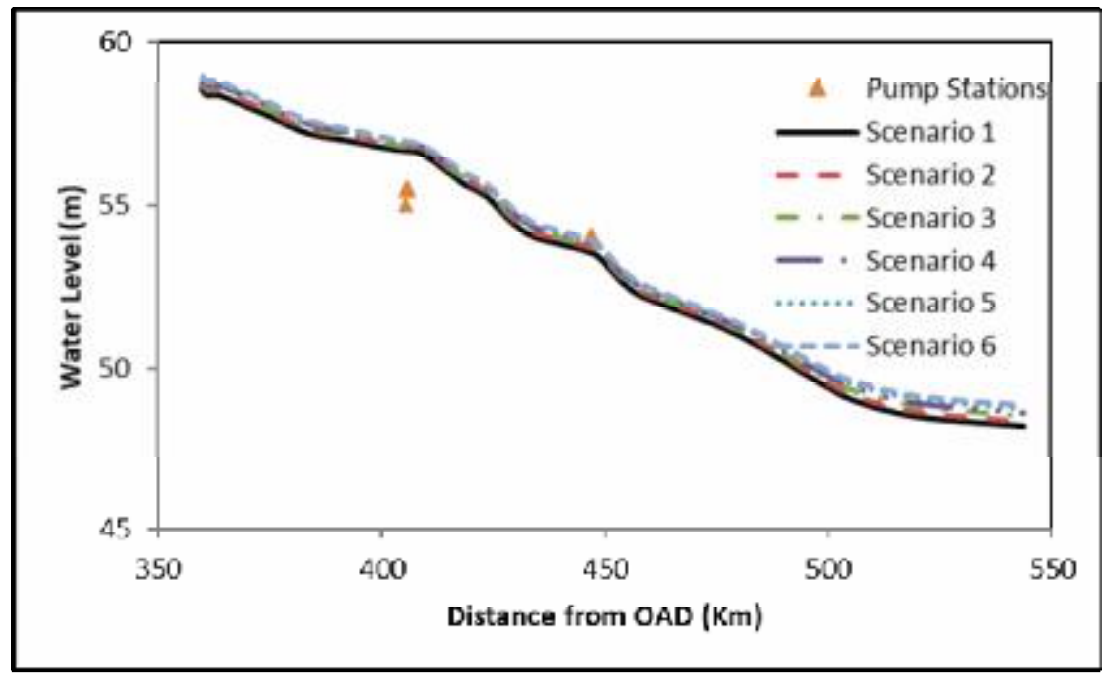

Fig. 8: Analysis results for the third reach.

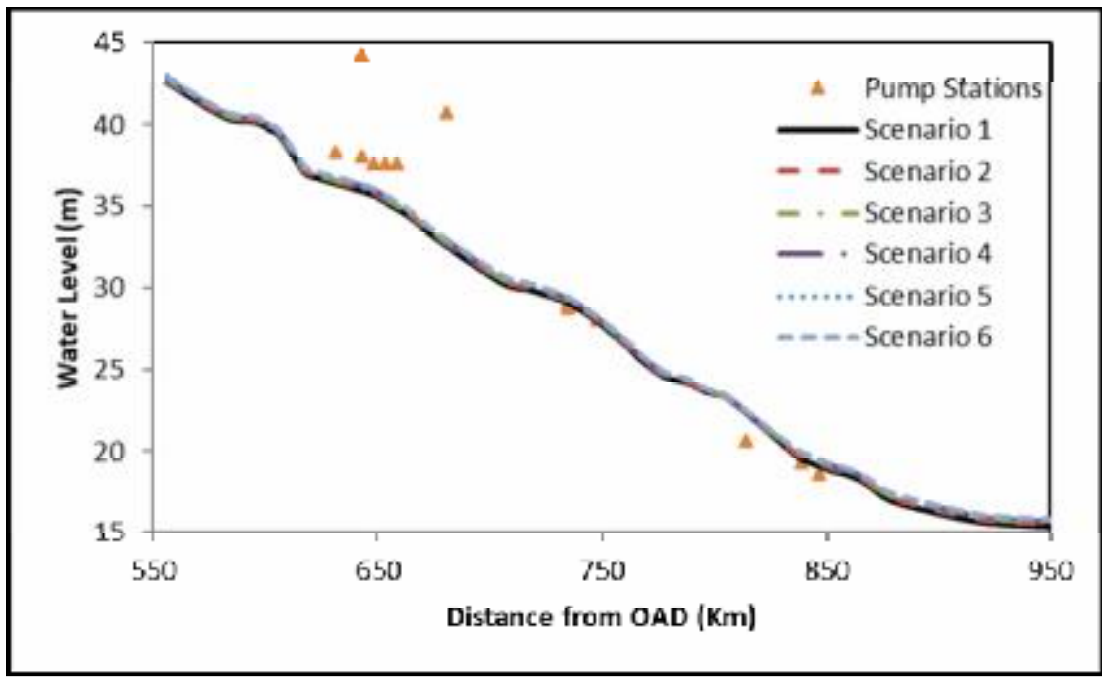

Fig. 9: Analysis results for the fourth reach.

\section{CONCLUSIONS AND RECOMMENDATIONS}

During this research, pump stations along all reaches from AOD to Delta Barrages were assessed according to their design and critical water level to determine the potential for expected problems in these reaches due to passing the low releases from AHDR as a result of construction of GERD. Several conclusions are drawn from this work:

1- A simulation model for AHDR was implemented to simulate the impact of construction of GERD on operating AHD and the change in the volume of water flowing from AHDR to Egypt. The model projected that, Egypt will suffer significant shortfalls relative to historical average releases from AHDR reaches to $3.76 \times 10^{9} \mathrm{~m}^{3} /$ year for scenario 6 (filling period 8 years), the annual deficit might grows and reaches to $10.48 \times 10^{9} \mathrm{~m}^{3} /$ year for scenario 1 (filling period 3 years). 
2- A mathematical model based on solving the energy and flow equations was developed to compute water levels related to the analyzed discharged. The computed water levels were compared to the design and critical pump station water level to determine the adequacy of the water level for pump station supply. The results indicated that the pumps in the first reach that will not operate for certain scenarios during the lowest discharges (in December) are ranging from $47 \%$ (scenario 1) to $23 \%$ (scenario 6). For the second reach, the pumps that would not operate for certain scenario would range between $41 \%$ (scenario 1) and $28 \%$ (scenario 6). For the third reach, the not operating pumps for certain scenario are $50 \%$ for all scenarios. For the fourth reach, the not operating pumps for certain scenario are $54 \%$ for all scenarios.

3 - If there are more than one pumping station serve the same area (For example for the same area we have 2 or 3 pumping stations serve this area and due to the reduction of flow and water level 1 or 2 of them is not operated but the others work, at this time only we can say that the non-operable pump stations are not important because this is the period of low requirements and we do not need to use all the pumps). This may not be serious for irrigation requirements in December and may be a few other months. Also we should check the water requirements and the crop pattern for each area served by pumps that cannot be operated to be sure about that.

4- It is recommended to review the critical operation water level for the pumping stations and importance of operating the affected pumps during reduction scenarios. In very important cases, it is recommended to construct additional intakes to cope with the lowest required scenario or using floating stations.

\section{REFERENCES}

[1] Abdel-Moteleb, M., and Saad, M. B. A., (2001), "Calibration Of An Ogee Weir," IAHR Congress, China.

[2] Ahmad, A. M., (2008), "Post-Jonglei Planning In Southern Sudan: Combining Environment With Development," Environment and Urbanization, Vol. 20, No. 2, 575-586, DOI 10.1177/0956247808096129.

[3] Carter R. W., and Godfrey R. G., (1960), "Storage And Flood Routing," United States Government Printing Office, Washington.

[4] Chow, V.T., (1957), Open Channel Hydraulics, McGraw-Hill Book Co., New-York, pp. 680.

[5] Chen, H., and Swain, A., (Mar. 2014) "The Grand Ethiopian Renaissance Dam: Evaluating Its Sustainability Standard and Geopolitical Significance," in Energy Development Frontier, Vol. 3 Iss. 1, PP. 11-19.

[6] Fahmy H., (2001), "Modification and Re-calibration of the Simulation Model of Lake Nasser," in International Water Resources Assocation, volume 26, Number 1, pp. 129-135.

[7] Georgakakos, A. P., Yao, H. and Miller, F., (May 1997), "A Decision Support System for the High Aswan Dam," Waterpower.

[8] Ghaas (1998), (visited on May 2018), "The Global River Discharge Database (Rivdis V1.1)," Internet site: http://www.rivdis.sr.unh.edu/cgi-bin/ViewSite?SITE=01487.

[9] Ismail, S. S., (2007), "Toshka Project Impacts On Water Levels And Discharges," Eleventh International Water Technology Conference, IWTC11 Sharm El-Sheikh, Egypt.

[10] Mersha, A. Z., Tesfaye, Wheeler K. and Ibrahim, Y., (October 6, 2014) "Reservoir Filling Options Assessment for the GERD using a probabilistic approach," in $4^{\text {th }}$ Nile Development Forum.

[11] Ministry of water resources and irrigation, (2005), "Water for the future, National water resources plan 2017," Cairo, Egypt.

[12] NRI (2010), Nile Research Institute Database, NRI, NWRC, Egypt.

[13] Sutcliffe, J. V. and Parks, Y. P. (1999), "The hydrology of the Nile, The International Assocation of Hydrological Sciences," IAHS Special Publication no. 5, ISBN 1-901502-75-9, UK.

[14] Yao, H., and Georgakakos, A. P., (June 2003), "Nile Decision Support Tool River Simulation And Management," Georgia Water Resources Institute (GWRI), Atlanta. 